\title{
Future thinking
}

The unexpected swell of action, sparked by a Swedish teenager, has put climate change back on the political radar. With time on their side, youth will experience longer term climate change impacts more than those in decision making positions, meaning they want a say in their future.

C limate marches, initiated by youth, are taking place with increased frequency at numerous locations around the world. This is not the first time that young people have taken a stand - there have been protests and activism in the past as well as legal cases, for example Juliana v. USA — but the current activism has, so far, sustained momentum, which seems to be have absent in the past.

Considering the legal actions that have been taken, the Juliana v. USA case was first filed in 2015 by 21 youths, on the basis that the government was failing to adequately protect the planet from the effects of climate change (https://go.nature.com/2Ggsfqo). The case cites the violation of the public trust doctrine that requires the government to protect public resources, such as land and water (essentially the climate system), for all to use, which is a violation of constitutional rights to life, liberty and property. Whilst it appears the case may not be successful, it is still ongoing, with appeals discussions scheduled for June 2019. This is not the only legal case relating to climate change issues (see Nat. Clim. Change 6, 655-656; 2016, for further examples and discussions), but it shows the motivation of teenagers to protect their future and gain a voice in the climate debate.

The IPCC Special Report on Global Warming of $1.5^{\circ} \mathrm{C}$ (https://www.ipcc.ch/ sr15/), released in October 2018, stated with high confidence, "The lower the emissions in 2030, the lower the challenge in limiting global warming to $1.5^{\circ} \mathrm{C}$ after 2030 with no or limited overshoot", which led to reporting that society has 12 years to fix climate change. The report highlighted the need for rapid and far-reaching transitions across sectors to lower emissions, all of which needs political will to commence. As Sonja Van Renssen highlights in a Feature in this issue, there is an intergenerational mismatch, with children born today likely to see out the century (which is where climate projections commonly stop) but not being heard in decisions about climate mitigation.

It is this lack of action that saw Greta Thunberg decide, at the end of a hot Swedish summer, to strike outside parliament. Beginning her strike from school on 20 August 2018, she was there every day for three weeks. The domestic media covered her
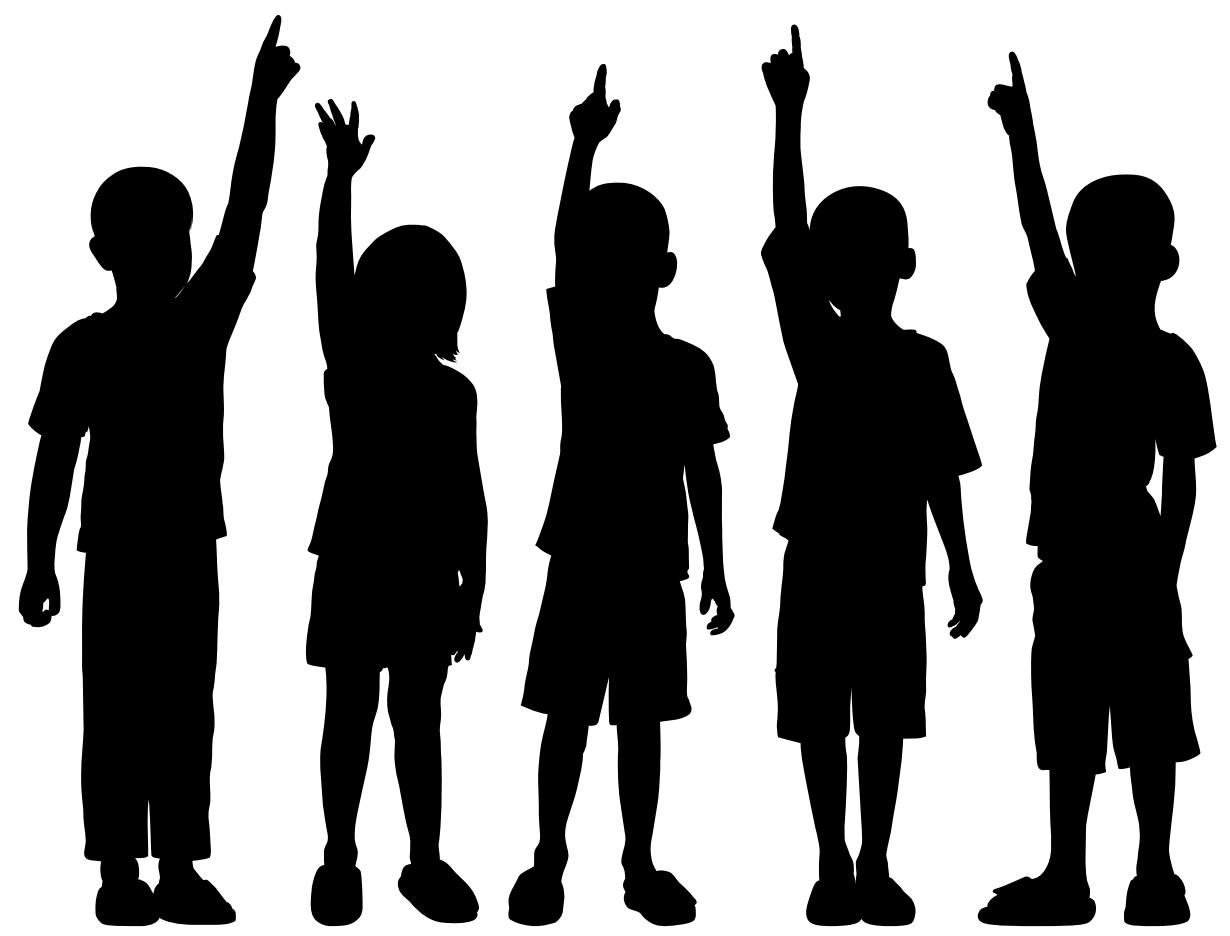

Credit: Leontura / DigitalVision Vectors / Getty

actions from the end of the first week, and then the word started to spread globally. While she returned to school after the initial three weeks, she continued to strike on Fridays and has inspired others to do the same, resulting in the creation of the \#FridaysforFuture movement. There have been numerous events around the world and whilst there is no centralised organisation of these events, the \#FridaysforFuture website has an interactive map of events. This action culminated on 15 March 2019 with an estimated 1.6-2 million young people and supporters striking and marching in over 125 countries.

There are 2.3 billion children worldwide, and they may by more vulnerable than adults to the effects of climate change due to a wide range of factors, including differences in anatomy, cognition, immunology, physiology and psychology (PLoS Med. 15, e1002627; 2018). A 2015 report by UNICEF (https:// go.nature.com/2KqTzq9) used IPCC Assessment Report 5 data to map potential climate change effects on children, with 1.45 billion projected to be severely affected in high impact areas under a business as usual scenario (RCP 8.5), compared to 150 million (still a large number) if warming is limited to $\sim 1.5^{\circ} \mathrm{C}$ (RCP 2.6). A case study in Malolos, in the Phillipines, found that climate change is already impacting the daily lives of children in a rural-urban transition zone, and that they typically use problem-focused coping to deal with the effects, while there is a lack of initiatives to mitigate climate change and its effects (Disaster Prev. Manag. 26, 217-229; 2017). Meanwhile, the latest report from UNICEF (https://go.nature. com/2ULY7LT) highlights risks to the 19 million children in Bangladesh, with extreme events and longer-term climate effects pushing families into poverty and displacement.

The current momentum in youth engagement with climate action needs to continue, and it is up to all of us to support, encourage and educate to ensure the future is as bright as we can make it.

Published online: 26 April 2019 https://doi.org/10.1038/s41558-019-0477-x 